\title{
Non-Contingent Exposure to Amphetamine in Adolescence Recruits miR-2I8 to Regulate Dcc Expression in the VTA
}

\author{
Santiago Cuesta', José Maria Restrepo-Lozano', Steven Silvestrin', Dominique Nouel', \\ Angélica Torres-Berrío, ${ }^{1,2}$, Lauren M Reynolds ${ }^{1,2}$, Andreas Arvanitogiannis ${ }^{3}$ and Cecilia Flores ${ }^{*, 1}$ \\ 'Department of Psychiatry and Department of Neurology and Neurosurgery, McGill University, Douglas Mental Health University Institute, \\ Montreal, QC, Canada; 'Integrated Program in Neuroscience, McGill University, Montreal, QC, Canada; ${ }^{3}$ Department of Psychology, Center for \\ Studies in Behavioral Neurobiology, Concordia University, Montreal, QC, Canada
}

\begin{abstract}
The development of the dopamine input to the medial prefrontal cortex occurs during adolescence and is a process that is vulnerable to disruption by stimulant drugs such as amphetamine. We have previously linked the amphetamine-induced disruption of dopamine connectivity and prefrontal cortex maturation during adolescence to the downregulation of the Netrin-I receptor, DCC, in dopamine neurons. However, how DCC expression in dopamine neurons is itself regulated is completely unknown. MicroRNA (miRNA) regulation of mRNA translation and stability is a prominent mechanism linking environmental events to changes in protein expression. Here, using male mice, we show that miR-2 18 is expressed in dopamine neurons and is a repressor of DCC. Whereas Dcc mRNA levels increase from early adolescence to adulthood, miR-218 exhibits the exact opposite switch, most likely maintaining postnatal Dcc expression. This dynamic regulation appears to be selective to Dcc since the expression of Robo I, the other guidance cue receptor target of miR-2 I 8, does not vary with age. Amphetamine in adolescence, but not in adulthood, increases miR-2 8 in the VTA and this event is required for druginduced downregulation of Dcc mRNA and protein expression. This effect seems to be specific to Dcc because amphetamine does not alter Robo I. Furthermore, the upregulation of miR-2 8 by amphetamine requires dopamine D2 receptor activation. These findings identify miR-2I 8 as regulator of DCC in the VTA both in normal development and after drug exposure in adolescence. Neuropsychopharmacology (2018) 43, 900-9|।; doi:I0.1038/npp.20 17.284; published online 20 December 2017
\end{abstract}

\section{INTRODUCTION}

Exposure to drugs, including amphetamine, have different long-term effects on the brain and on behavior depending on the age at the first exposure. Epidemiological studies have shown, for example, that drug use in adolescence is associated with an elevated risk for lifetime abuse and dependence (Grant and Dawson, 1998; McCabe et al, 2007; Swendsen et al, 2012). Although it is easy to imagine that stimulant drugs disrupt the patterns of neural networks that are still developing during adolescence, it is only recently that we have begun to understand the molecular mechanisms by which they interact with ongoing developmental processes in adolescence to induce enduring changes in brain connectivity and function.

Reorganization of dopamine input connectivity of the medial prefrontal cortex is one of the most notable developmental events observed in the brain in adolescence (Manitt et al, 2013, 2011; Money and Stanwood, 2013; Reynolds et al, 2015) and, as such, is an obvious target of

* Correspondence: Dr C Flores, Douglas Mental Health University Institute, Perry Pavilion, Room \# 2111, 6875 LaSalle Blvd. Montreal (Verdun), QC H4H IR3, Canada, Tel: +5I4 76I 6I3I ext: 28I4,

Fax: +514 762 3034, E-mail: cecilia.flores@mcgill.ca

Received 31 July 2017; revised 2 November 2017; accepted 6 November 2017; accepted article preview online 20 November 2017 disruption by stimulant drugs. Our work in rodents has identified the Netrin-1 receptor, Deleted in Colorectal Cancer (DCC), as a key mediator for medial prefrontal cortex dopamine connectivity in adolescence and its disruption by drugs (Flores, 2011; Manitt et al, 2013, 2011; Reynolds et al, 2017). We have shown that DCC receptors within mesolimbic dopamine axons promote target recognition events in the nucleus accumbens, thereby preventing them to grow ectopically to the medial prefrontal cortex. By limiting the extent of the dopaminergic input to the medial prefrontal cortex, DCC receptors influence the organization and function of local synaptic circuitry and cognitive processing (Manitt et al, 2013; Reynolds et al, 2017). What is more, DCC expression in dopamine neurons is altered after drug exposure: amphetamine treatment in early adolescence downregulates DCC protein expression in ventral tegmental (VTA) dopamine neurons (Yetnikoff et al, 2011). As a result, amphetamine in adolescence leads to (a) altered dopamine innervation to the medial prefrontal cortex, (b) reorganization of medial prefrontal cortex local circuitry, and (c) impaired cognitive function in adulthood (Reynolds et al, 2015). These results indicate that variations in DCC receptor expression in dopamine neurons and specifically in adolescence influence the developmental trajectory of dopamine neurons and, therefore, adult medial prefrontal cortex function. However, how DCC expression is 
regulated during the normal course of adolescent development and whether this process is disrupted by stimulant drugs is not known.

MicroRNA regulation of mRNA translation and stability is a prominent mechanism linking environmental events to changes in protein expression (Codocedo and Inestrosa, 2016; Hollins and Cairns, 2016). Recently, we demonstrated that the microRNA-218 (miR-218) is a potent repressor of DCC expression in human and mouse medial prefrontal cortex pyramidal neurons (Torres-Berrío et al, 2017). In fact, we showed that downregulation of miR-218 mediates stressinduced upregulation of Dcc mRNA and protein expression in the adult medial prefrontal cortex (Torres-Berrío et al, 2017). Because microRNAs are emerging as master regulators of many cellular processes, including those involved in brain development (Hollander et al, 2010; Hollins and Cairns, 2016; Im et al, 2010; Issler and Chen, 2015; Rao and Pak, 2016; Sun et al, 2013; Torres-Berrío et al, 2017), we hypothesize that $\mathrm{miR}-218$ is the key regulator of DCC expression in dopamine neurons and the molecule that serves as a sensor of environmental perturbations, including exposure to amphetamine in adolescence. First, we determined if miR-218 is expressed by VTA dopamine neurons and whether its expression varies across postnatal life according to changes in DCC levels. We then assessed the possibility that amphetamine in adolescence, in comparison to adulthood, recruits miR-218 in dopamine neurons to repress DCC. Finally, we assessed whether dopamine D2 or $\mathrm{D} 1$ receptor activation is required for miR-218 signaling.

\section{MATERIALS AND METHODS}

\section{Animals}

All experiments and procedures were performed in accordance with the guidelines of the Canadian Council of Animal Care and the McGill University/Douglas Mental Health University Institute Animal Care Committee. Male C57BL/6 wild-type mice were obtained from Charles River Canada and maintained in the colony room of the Douglas Mental Health University Institute Neurophenotyping center on a 12-h light-dark cycle (light on at $0800 \mathrm{~h}$ ) with food and water available ad libitum. All the experiments were conducted during the light part of the cycle.

\section{In Situ Hybridization}

Adult male C57BL/6 mice were anesthetized using an overdose of intraperitoneal ketamine $50 \mathrm{mg} / \mathrm{kg}$, xylazine $5 \mathrm{mg} / \mathrm{kg}$, and acepromazine $1 \mathrm{mg} / \mathrm{kg}$, and perfused intracardially with $50 \mathrm{ml}$ of $0.9 \%$ saline followed by $75 \mathrm{ml}$ of chilled fixative solution (2\% paraformaldehyde in phosphatebuffered solution). After removal, brains were rapidly frozen in dry ice-cooled 2-methylbutane (Fisher Scientific, Hampton, NH, USA). Coronal sections of the VTA at $12 \mu \mathrm{m}$ were obtained using a cryostat, were mounted onto superfrost slides and endogenous peroxidase was inactivated with $0.3 \%$ $\mathrm{H}_{2} \mathrm{O}_{2}$. Slices were then permeabilized with Proteinase $\mathrm{K}$ solution and underwent acetylation with triethanolamine and acetic anhydride. Sense and antisense 5' digoxigeninlabeled LNA probes against miR-218 (hsa-miR-218-5p: 5'-ACATGGTTAGATCAAGCACA-3'; Exiqon, Vedbaek,
Denmark) were then hybridized to the slices for $14 \mathrm{~h}$ at $60{ }^{\circ} \mathrm{C}$. After hybridization, brain sections were stringently washed in saline-sodium citrate (SSC) and $50 \%$ formamide for $30 \mathrm{~min}$ at $60^{\circ} \mathrm{C}$, treated with RNAse A for $30 \mathrm{~min}$ at $37^{\circ} \mathrm{C}$ and washed in decreasing concentrations of SSC. VTA tissue was incubated overnight at $4{ }^{\circ} \mathrm{C}$ with an anti-DIG antibody coupled to horseradish peroxidase (Roche, Mississauga, ON, Canada) and rabbit polyclonal anti-Tyrosine Hydroxylase (TH) antibody (1:500 dilution, catalog \#AB152, RRID: AB_390204; Millipore Bioscience Research Reagents) or rabbit polyclonal anti-DCC No. 2473 (1:200) (Manitt et al, 2010). To reveal miRNA expression, sections were incubated with tyramide-coupled to Cy3 (Perkin Elmer, Montréal, QC, Canada) and Alexa 488-coupled secondary antibody raised in goat (Life Technologies, Toronto, ON, Canada) to reveal $\mathrm{TH}$ immunofluorescence. Sections were rinsed in PBS and coverslipped with DAPI containing media (Vector laboratories, Burlingame, CA, USA).

\section{Drugs}

D-Amphetamine sulfate (Sigma-Aldrich, Dorset, United Kingdom) was dissolved in $0.9 \%$ saline. All amphetamine injections were administered i.p. at a volume of $0.1 \mathrm{ml} / 10 \mathrm{~g}$ and at a dose of $4 \mathrm{mg} / \mathrm{kg}$ of amphetamine. Raclopride (Sigma-Aldrich, Dorset, United Kingdom) was dissolved in $0.9 \%$ saline and the $\mathrm{pH}$ was adjusted to 7.4. SCH 23390 (Tocris Bioscience, Bristol, United Kingdom) was dissolved in $0.9 \%$ saline. All raclopride and SCH 23390 injections were administered i.p. at a volume of $0.1 \mathrm{ml} / 10 \mathrm{~g} 30 \mathrm{~min}$ prior each amphetamine injection. The dose used for raclopride was $1 \mathrm{mg} / \mathrm{kg}$ and the dose used for $\mathrm{SCH} 23390,0.1 \mathrm{mg} / \mathrm{kg}$ (Fan and Hess, 2007).

Amphetamine treatment protocol. Male C57BL/6 mice received one injection of amphetamine $(4 \mathrm{mg} / \mathrm{kg})$ or vehicle (saline), once every other day, for a total of 5 days. Mice were treated during early adolescence, from postnatal day (PND) $22 \pm 1$ to PND $31 \pm 1$, or in adulthood, from PND $75 \pm 15$ to PND $84 \pm 15$. This exact drug regimen, when administered in adolescence, but not in adulthood, decreases DCC receptor expression in the VTA 1 week after the last injection (Yetnikoff et al, 2011). Consistent with our previous work, we define early adolescence in mice as the period between the day of weaning and PND 32 (Manitt et al, 2013; Reynolds et al, 2015; Yetnikoff et al, 2011); this definition seems now to be a consensus in the rodent literature (Spear, 2000; Laviola et al, 2003; Schneider, 2013; Tirelli et al, 2003). This is not an absolute margin, but rather an age range during which mice exhibit distinct neurobehavioral characteristics. Horizontal activity was measured $15 \mathrm{~min}$ prior and $90 \mathrm{~min}$ after each saline or $\mathrm{AMPH}$ injection.

\section{RNA Extraction and Quantitative Real-Time PCR for Mouse Tissue}

One week after either early adolescent or adult amphetamine treatment, bilateral punches of the VTA were taken from coronal sections obtained as described previously (Manitt et al, 2010). Briefly, after mice euthanasia, brains were then removed and rapidly frozen in dry ice-cooled 
2-methylbutane (Fisher Scientific, Hampton, NH, USA). Bilateral punches of the VTA were excised from 1-mm-thick coronal slices starting from sections corresponding to Plate 55 of Paxinos and Franklin (2001). Total RNA and microRNA fraction were isolated from the mouse frozen tissue with the miRNeasy Micro Kit protocol (Qiagen, Toronto, ON, Canada) as previously (Torres-Berrío et al, 2017). All mouse RNA samples were determined to have $260 / 280$ and $260 / 230$ values $\geqslant 1.8$, using the Nanodrop 1000 system (Thermo Scientific, Toronto, ON, Canada). Furthermore, we assessed RNA integrity using the denaturing gel electrophoresis method proposed by Aranda et al (2012) and detected the three well-defined 28S, 18S, and 5.8S/5S ribosomal bands without any background. Reverse transcription for Dcc, Roundabout homolog 1 (Robo1), and Glyceraldehyde-3-phosphatedehydrogenase (GAPDH) mRNA were performed using a High-Capacity cDNA Reverse Transcription Kit (Applied Biosystems, Foster City, CA) according to manufacturer's instructions. Real time PCR, using TaqMan assay (Applied Biosystems, Foster City, CA) was carried out with an Applied Biosystems 7900HT RT PCR system. Data for Dcc and Robo1 mRNA expression were analyzed by using the absolute quantification (AQ) standard curve method and the levels of these transcripts were relativized to the expression of the reference gene Gapdh. Reverse transcription for miR-218 was performed using the TaqMan MicroRNA Reverse Transcription Kit together with the corresponding miRNA TaqMan probes (Applied Biosystems, Foster City, CA) and expression levels were calculated using AQ standard curve method. The small nucleolar RNA (snoRNA) RNU6B was used as endogenous control to normalize the expression of miR-218. In all cases, the real-time PCR was run in technical triplicates.

\section{Protein Extraction and Western Blot Analysis}

In total, $0.3 \mathrm{ml}$ of $100 \%$ ethanol was added to the remaining interphase and phenol phase separated from the total RNA extraction, incubated at room temperature for $3 \mathrm{~min}$ and centrifugated at $2000 \mathrm{~g}$ at $4^{\circ} \mathrm{C}$ for 2 min to sediment DNA. The phenol/ethanol supernatant was transferred to a new tube and mixed with $1.5 \mathrm{ml}$ of isopropanol, incubated for $10 \mathrm{~min}$ and centrifugated at $12000 \mathrm{~g}$ for $10 \mathrm{~min}$ at $4{ }^{\circ} \mathrm{C}$ to precipitate the protein. After removal of the supernatant, the pellet was washed three times with $2 \mathrm{ml}$ of $100 \%$ ethanol solution, air dried and resuspended in TNE buffer $(50 \mathrm{mM}$ Tris- $\mathrm{HCl}, \mathrm{pH} 7.4,150 \mathrm{mM} \mathrm{NaCl}, 1 \%$ Nonidet P-40, 1\% Triton X-100, 0.1\% SDS and $1 \mathrm{mM}$ EDTA) supplemented with phosphatase and protease. Protein extracts were heated to $95^{\circ} \mathrm{C}$ for $5 \mathrm{~min}$ with Laemmli buffer as a reducing treatment and processed for western blot as before (TorresBerrío et al, 2017). Antibodies: anti-DCC (1:1000, Cat\#554223, RRID: AB_395314, BD Pharmingen, Mississauga, Canada), anti-ROB̈O1 (1:1500, Cat\#ab85312, Abcam, Toronto, Canada), and anti- $\beta$-actin (1:15 000, Sigma-Aldrich, Oakville, ON, Canada).

\section{Locked Nucleic Acid Oligonucleotides Preparation}

In vivo LNA oligonucleotides targeting miRNA-218-5p (antimiR-218; MIMAT0000663; mmu-miR-218-5; sequence: 5'-UUG UGC UUG AUC UAA CCA UGU-3') and scramble
(Scramble, sequence: 5'-GGT TAG ATC AAG CAC A-3') were customized and synthetized by Exiqon (Vedbaek, Denmark). This technology was developed to inhibit a specific microRNA in vivo and induce its degradation (Hollander et al, 2010; Im et al, 2010; Krutzfeldt et al, 2007). Both LNA oligonucleotides were dissolved in sterile PBS (pH 7.4).

\section{Stereotaxic Surgery and LNA Oligonucleotides Administration}

One day before the starting of the amphetamine regimen, at PND21 \pm 1 , mice were anesthetized with isoflurane (5\% for induction and $2 \%$ for maintenance) and placed in a stereotaxic apparatus. Simultaneous bilateral microinfusions of LNA oligonucleotides containing the antimiR-218 or scramble sequences (Exiqon, Vedbaek, Denmark) into the VTA were performed stereotaxically using Hamilton syringes. VTA coordinates: $-2.56 \mathrm{~mm}$ (anterior/posterior), $+0.9 \mathrm{~mm}$ (lateral), and $-4.1 \mathrm{~mm}$ (dorsal/ventral) relative to Bregma, at a $10^{\circ}$ angle as previously (Manitt et al, 2013). A total of $0.5 \mu \mathrm{l}$ of LNA oligonucleotides solution was delivered on each side over an 8 -min period followed by a pause of $6 \mathrm{~min}$.

\section{Experimental Design}

The experimental design and procedures employed in this study are indicated with diagrams on each figure.

\section{Statistical Analysis}

All values are represented as means \pm SEM. A significance threshold of $\alpha=0.05$ was used in all the experiments. Statistical differences between two groups were analyzed with Student's $t$-tests. Correlations were calculated using the Pearson correlation coefficient with two-tailed analysis on the fold-change data. All data are normally distributed and the variance is similar between groups. Statistical differences between more than two groups were analyzed with one-way, two-way, or two-way repeated-measures ANOVAs, followed by Bonferroni multiple comparison post hoc tests. The sample size in all the experiment varied from 4 to 8 animals per group.

\section{RESULTS}

\section{Expression of miR-218 in Dopamine Neurons in the VTA}

Combined in situ hybridization and immunofluorescence experiments show that miR-218 is highly expressed by dopamine neurons in the adult VTA (Figure 1a). Careful qualitative inspection revealed that miR-218 expression is confined to TH-positive neurons (Figure 1b). The expression of miR-218 to a specific subpopulation of neurons within one region is consistent with previous reports showing that in the hippocampus miR-218 is specifically enriched in pyramidal neurons compared to neuropeptide somatostatin expressing GABAergic interneurons or to microglia, astrocytes and oligodendrocytes (Butovsky et al, 2014; He et al, 2012). We find DCC and miR-218 coexpression in the adult VTA (Figure 1c). 
a
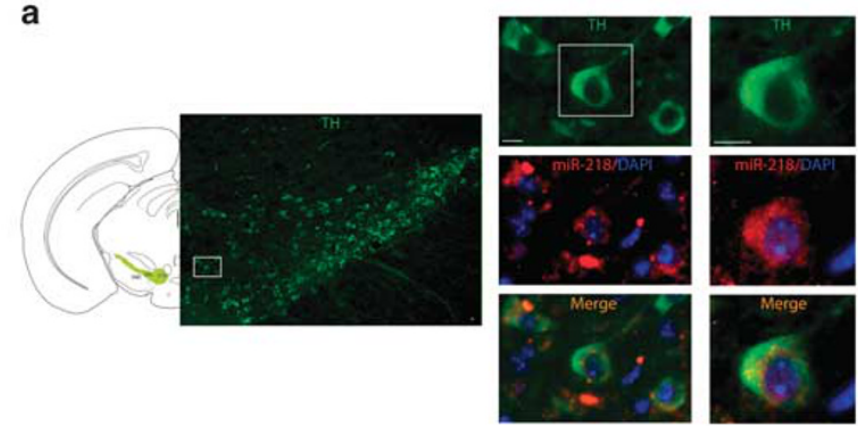

b
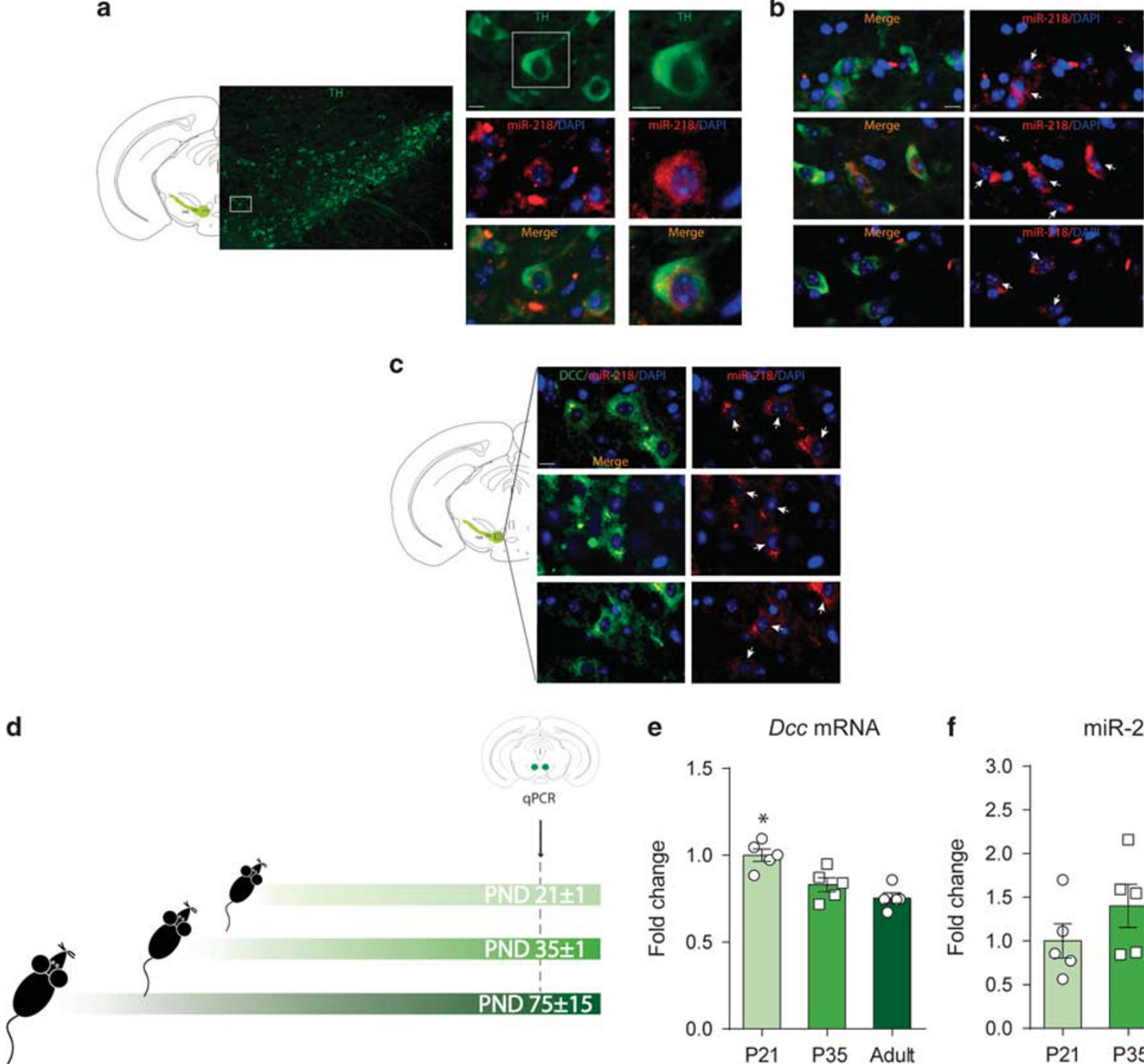

e

Dcc mRNA
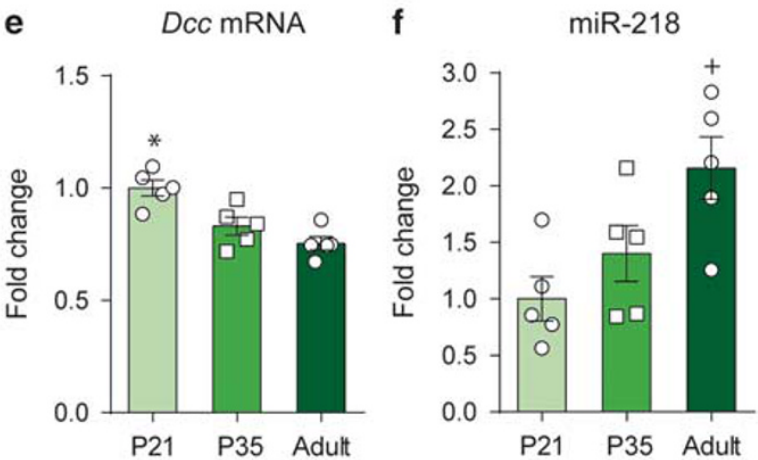

g

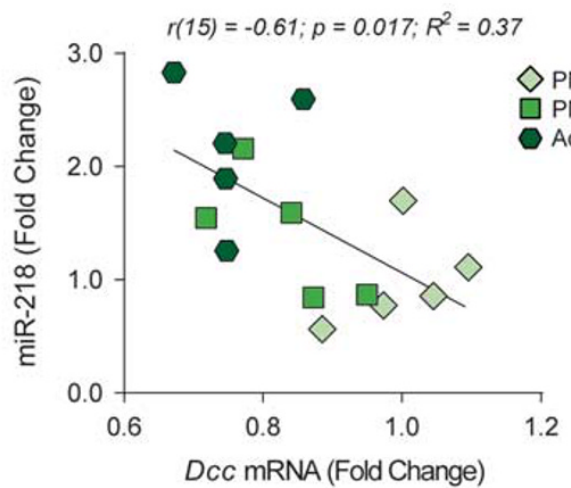

h

Robo1 mRNA

i

Dcc:Robo1 mRNA
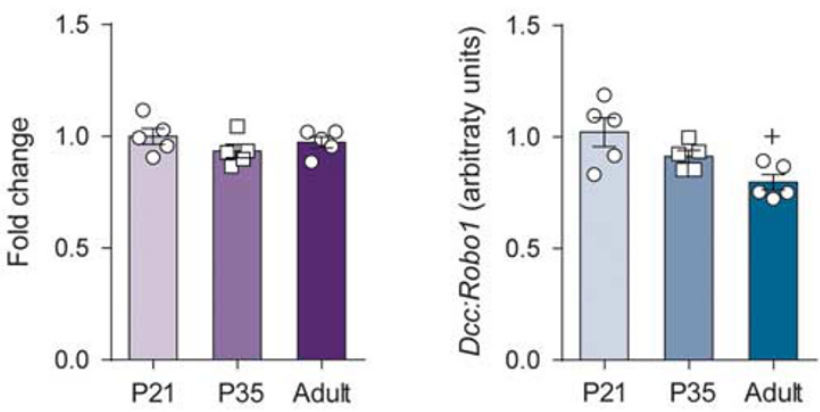

Figure I Dopamine neurons expressed miR-218, with levels varying across postnatal development. (a) Representative low- and high-magnification micrographs of coronal sections from an adult mouse showing miR-2 8 (red) expression in tyrosine hydroxylase (TH) positive neurons (green) in the VTA. Scale bar $10 \mu \mathrm{m}$. (b) MiR-2I 8 is confined to TH-positive neurons (white arrows). Scale bar $10 \mu \mathrm{m}$. (c) Co-expression of DCC (green) and miR-2I 8 (red) in the adult VTA (white arrows). Scale bar $10 \mu \mathrm{m}$. (d) Timeline and experimental procedures. (e) Levels of Dcc mRNA in the VTA of mice at three different postnatal ages. ( $f$ Levels of miR-2I 8 in mice at three different postnatal ages. Note the opposite dynamic expression pattern of Dcc and miR-2I 8 and the switch in levels of expression from early adolescence to adulthood (*significantly different from the other ages, $p<0.05$. ${ }^{+}$significantly different from adulthood, $p<0.05)$. (g) There is a negative correlation between Dcc and miR-2 8 expression in the VTA during postnatal development. (h) The levels of expression of another miR-2 8 target, Robo I, do not change in the VTA from early adolescence to adulthood. (i) There is an adolescent switch in the Dcc:Robo I mRNA expression ratio in the VTA with predominance of Robo I mRNA expression in adulthood vs adolescence ( ${ }^{+}$significantly different from adulthood, $p<0.05$ ). All data are shown as mean \pm SEM. DAPI, 4',6-diamidino-2-phenylindole; SNC, substantia nigra pars compacta; SNR, substantia nigra pars reticulata. 
miR-218 and Dcc Levels are Opposite in the Postnatal VTA with Expression Switching in Adolescence

We have shown that DCC receptors are conspicuously expressed by VTA dopamine neurons throughout life, but that levels decrease from adolescence onwards (Manitt et al, 2010). Thus, we hypothesized that if miR-218 controls Dcc gene expression, its levels should be opposite to those of $D c c$ and should also shift from adolescence into adulthood. To address this issue, we measured miR-218 and Dcc mRNA expression in tissue punches excised from the VTA of PND21 \pm 1, PND35 \pm 1 , and PND75 \pm 15 mice (Figure 1d). We find that, similar to DCC protein expression, Dcc mRNA levels are high in early adolescence, but begin to significantly decrease afterwards (Figure 1e; one-way ANOVA: $F_{(2,12)}=12.70, p=0.0011$; values at PND21 are significantly higher than at PND35 and PND75; post hoc Bonferroni, $p<0.05)$. Importantly, miR-218 expression is opposite to $D c c$ mRNA expression at all ages examined, it changes from low to high from adolescence to adulthood (Figure 1f; one-way ANOVA: $F_{(2,12)}=5.89, p=0.0017$; values at PND21 are significantly lower than at PND75; post hoc Bonferroni, $p<0.05)$. There is a significant negative correlation between postnatal Dcc mRNA and miR-218 expression, suggesting that miR-218 controls Dcc mRNA expression in the VTA across the lifespan $\left(r_{(15)}=-0.61 ; p=0.02 ; \quad R^{2}=0.37\right)$ (Figure 1g).

In addition to $D c c$, miR-218 has been shown to repress the expression of another guidance cue receptor gene, Robo1 (Small et al, 2010; Thiebes et al, 2015; Torres-Berrío et al, 2017), which is also expressed by VTA dopamine neurons in rodents (Marillat et al, 2002). Therefore, we determined VTA Robo1 mRNA expression at the three different postnatal ages. Unlike Dcc mRNA levels, Robo1 expression remains constant across postnatal life (Figure 1h; one-way ANOVA: $\left.F_{(2,12)}=1.17\right)$. Thus, whereas the developmental expression of Dcc in the VTA is controlled by opposite variations in miR-218 levels, Robo1 expression is not sensitive to these changes. This result is in line with the fact that miRNA control of mRNA expression has spatiotemporal specificity and is dependent on the rate of transcription of a particular gene (Mukherji et al, 2011; Sambandan et al, 2017). Whether
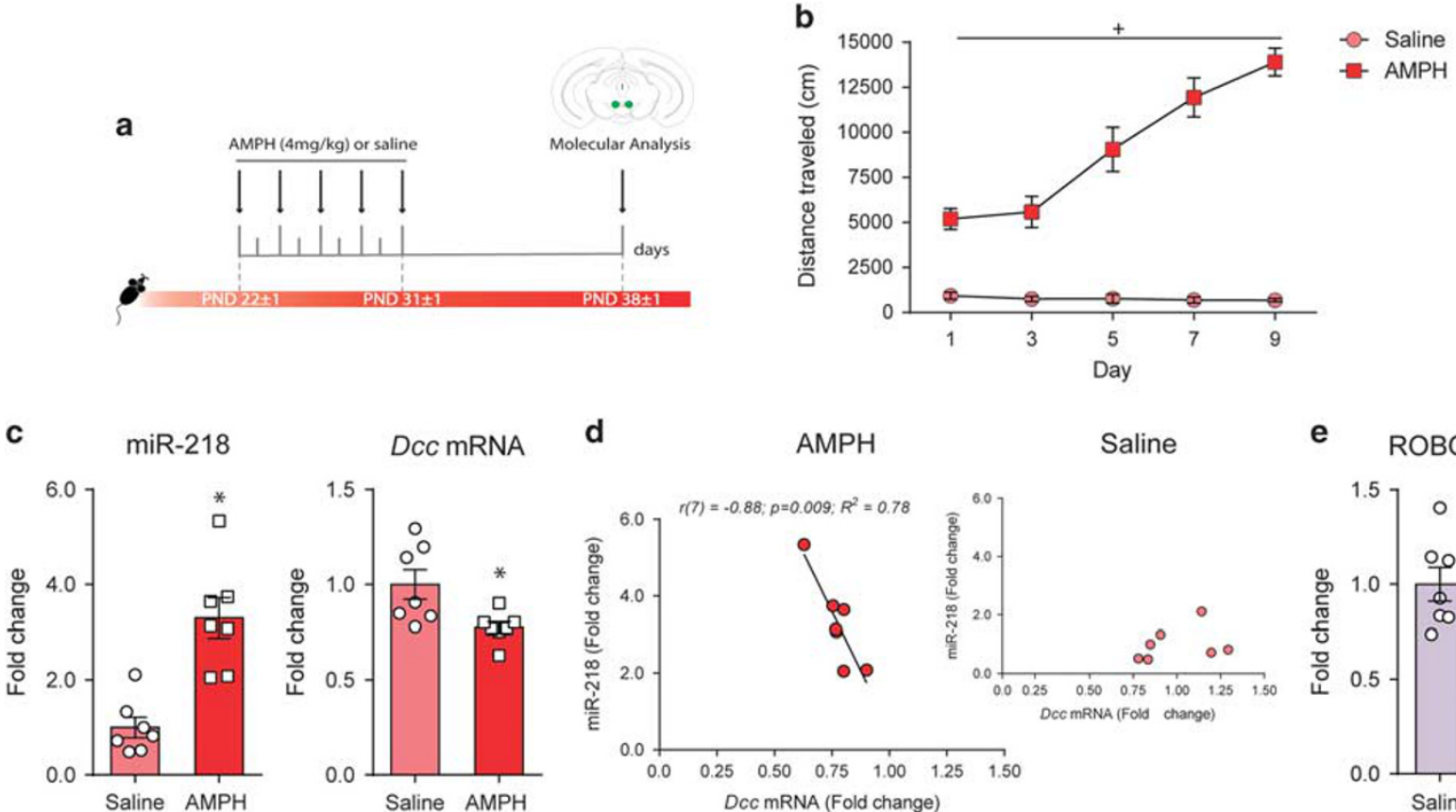

d

$\mathrm{AMPH}$
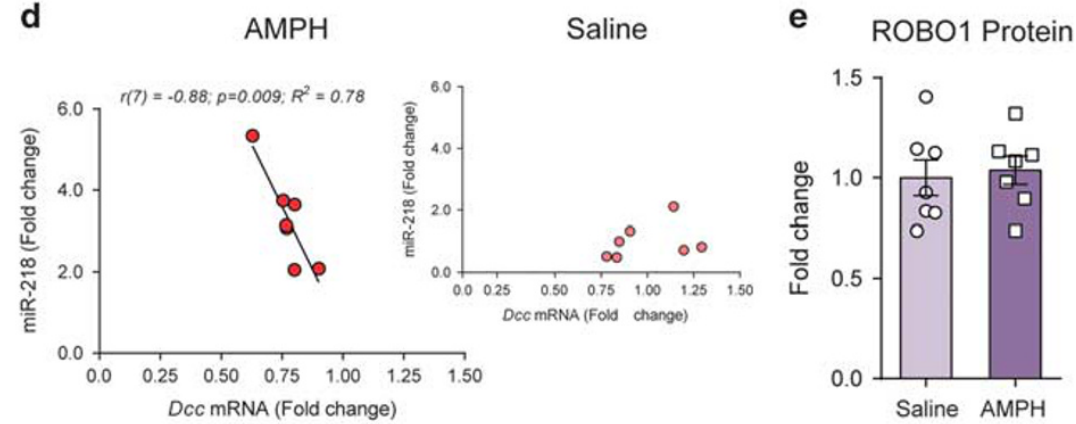

f Adult treatment
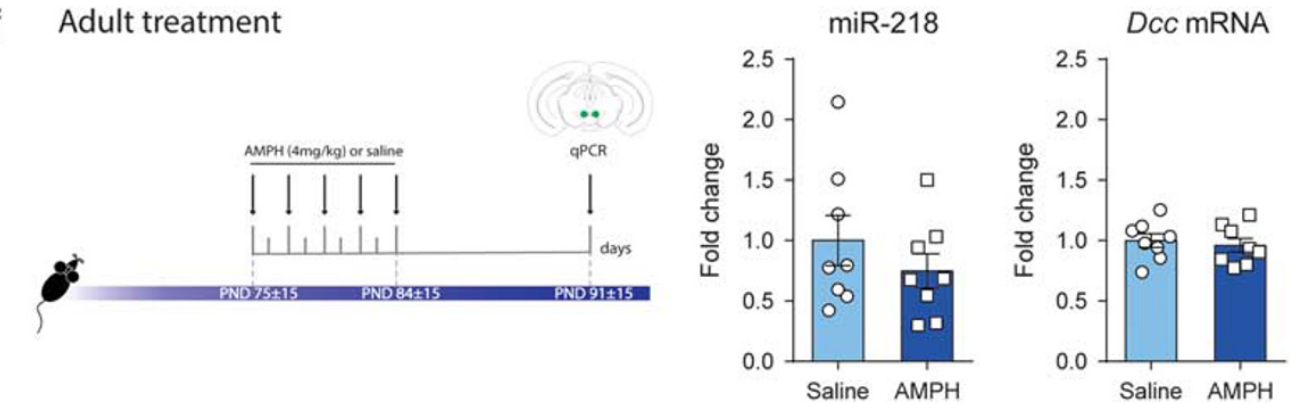

Figure 2 Amphetamine in adolescence upregulates miR-218, but downregulates Dcc mRNA expression in the VTA. (a) Timeline of treatment and experimental procedures. (b) Locomotor activity during the 90 min test performed after each treatment injection; ${ }^{+}$significantly different from saline group, $p<0.05$. (c) MiR-2 8 expression in the VTA is significantly increased in the VTA one week after amphetamine (AMPH) treatment in adolescence; *significantly different from saline group, $p<0.05$. (d) There is a negative correlation between miR-2 8 and Dcc mRNA expression in the VTA in the amphetamine-treated group, but not in saline controls. (e) AMPH exposure during adolescence does not change ROBOI protein expression. (f) The exact same amphetamine regimen given during adulthood fails to alter miR-2I 8 or Dcc mRNA expression in the VTA I week later. All data are shown as mean \pm SEM. 
Robol is expressed in VTA neurons other than dopamine cells and/or its transcription rate is outside the range of miR-218 regulation needs to be determined.

In motor neurons, $\mathrm{ROBO} 1$ receptor activation has been shown to switch off DCC-mediated Netrin-1 attraction (Dudanova and Klein, 2013). Then, we measured the relative levels of Dcc and Robol mRNA in the VTA within each subject (ie, Dcc:Robol mRNA ratio). We find that a significant shift towards Robol predominance occurs from PND21 to adulthood (Figure 1i, one-way ANOVA: $F_{(2,12)}=6.19, p=0.014$; values at PND21 are significantly higher than at PND75; post hoc Bonferroni, $p<0.05)$. This finding is intriguing considering the critical role that DCCmediated Netrin-1 signaling plays on axon targeting in the nucleus accumbens in adolescence, controlling in turn dopamine input to the medial prefrontal cortex (Reynolds et al, 2017). Robol receptors may contribute to this process.

\section{Amphetamine in Adolescence Upregulates miR-218, but Downregulates Dcc mRNA Expression in the VTA}

Next, we measured miR-218 in the VTA following amphetamine exposure in adolescence (Figure 2a). Figure $2 \mathrm{~b}$ shows the locomotor activity displayed by mice after each amphetamine or saline injection. As expected, amphetamine-treated animals show higher activity compared with saline controls during all the sessions (two-way ANOVA for repeated measures: main effect of treatment, $F_{(1,12)}=193.3, p<0.0001$; main effect of the day, $F_{(4,48)}=21.09$; $p<0.0001$; and significant treatment $\times$ day interaction, $F_{(4,48)}=23.01, \quad p<0.0001$. Post hoc Bonferroni; significant differences between amphetamine and saline in distance traveled each day, $p<0.001)$. Amphetamine exposure in early adolescence, in comparison to saline, produces a large increase ( $\sim 2.5$ fold) in miR-218 expression in the VTA 1 week later (Figure $\left.2 c ; t_{(12)}=4.82, p=0.0004\right)$. Amphetamine decreases Dcc mRNA expression in this region (Figure 2c; $t_{(12)}=2.70$, $p=0.02$ ). This result is in line with our previous reports of decreased DCC protein expression (Yetnikoff et al, 2011), suggesting that amphetamine in adolescence controls DCC receptor at the levels of transcription. Interestingly, there is a significant negative correlation between miR-218 and Dcc mRNA expression in the VTA in the amphetamine group, but not in saline-treated mice (Figure $2 \mathrm{~d} ; r_{(7)}=-0.88, p=0.009$, $\left.R^{2}=0.78\right)$. This finding suggests that amphetamine induces increases in miR-218 levels that are high enough to downregulate $D c c$ mRNA expression. The effects of amphetamine on miR-218 and Dcc expression are robust: we replicated them in a second cohort of mice.

To verify if the increase in miR-218 levels induced by amphetamine in the VTA affect the expression of the other receptor guidance cue, $\mathrm{ROBO} 1$, we extracted the protein fraction from the samples used in our original cohort. We found that ROBO1 expression is not altered by amphetamine treatment in the VTA (Figure $2 \mathrm{e} ; t_{(12)}=0.33, p=0.75$ ).

\section{Adult Exposure to Amphetamine Does Not Alter miR-218 or Dcc mRNA Expression in the VTA}

To determine whether the effects of amphetamine on miR-218 and Dcc mRNA expression are restricted to the adolescent period, we conducted the exact same experiment, but in adult mice. Animals were treated from PND75 \pm 15 to PND84 \pm 15 and euthanized 1 week after (Figure 2f). In contrast to adolescent exposure, amphetamine in adulthood does not alter miR-218 or Dcc mRNA expression in the VTA (Figure 2f; miR-218: $t_{(14)}=0.99, \quad p=0.34 ;$ Dcc mRNA $\left.t_{(14)}=0.50, p=0.62\right)$.

\section{miR-218 Is Required for Amphetamine-Induced Downregulation of $D c c$ in the VTA}

To directly demonstrate that amphetamine downregulates Dcc mRNA expression in the VTA by upregulation of miR-218, we used LNA oligonucleotide technology ('antagomiRs'). Based on previous reports (Hollander et al, 2010; Im et al, 2010; Krutzfeldt et al, 2007), we first tested two different concentrations of LNA oligonucleotides $(0.3 \mathrm{mM}$ and $0.6 \mathrm{mM}$ ) by microinfusing them bilaterally into the VTA and assessing miR-218 levels 10 days later. Since both doses were equally efficient in reducing VTA miR-218 expression, we selected the lowest dose $(0.3 \mathrm{mM})$ to minimize undesirable effects.

One day before the start of the amphetamine or saline treatment, mice received bilateral VTA microinfusions of an antagomiR with scramble sequence (Scramble) or with antimiR-218 (Figure 3a). There were four groups: Scramble-saline, Scramble-amphetamine, antimiR-218-saline, and antimiR-218-ampehtamine. The behavioral analysis revealed no effects of the antimiR-218 microinfusion on locomotor activity observed in mice treated with amphetamine or saline (Figure 3b; three-way ANOVA for repeated measures, main effect of treatment, $F_{(1,26)}=112.20, p<0.0001$, post hoc Bonferroni; significant differences Scramble-amphetamine and antimir-218-amphetamine $v s$ Scramble-saline and antimir-saline in the distance traveled each day; $p<0.05$ ). As expected, in mice with microinfusions of the Scramble sequence, amphetamine treatment significantly increases miR-218 expression in comparison to their saline counterparts. In contrast, in mice with antimiR-218 microinfusions, miR-218 is reduced $(\sim 70 \%)$ in comparison to mice with Scramble sequence, regardless of treatment. Furthermore, in the antimiR-218 group, there are no differences in miR-218 expression between amphetamine and saline groups. (Figure 3c; two-way ANOVA: main effect of microinfusion, $F_{(1,26)}=59.66, \quad p<0.0001 ;$ main effect of treatment, $F_{(1,26)}=8.91 ; p=0.0040 ;$ and significant microinfusion $\times$ treatment interaction, $F_{(1,26)}=8.67, p=0.0045$, post hoc Bonferroni; significant differences Scramble-amphetamine $v s$ all the other groups, antimiR-218-saline and amphetamine $v s$ Scramble-saline; $p<0.05$ ).

MiR-218 degradation blocked the downregulation of Dcc mRNA expression induced by amphetamine in the VTA. As anticipated, amphetamine induced a downregulation of Dcc mRNA expression in mice with scramble sequence microinfusions. This reduction, however, was abolished by the antimiR-218 microinfusion (Figure 3c; two-way ANOVA: main effect of treatment, $F_{(1,26)}=10.65, p=0.031$, significant microinfusion $\times$ treatment interaction, $F_{(1,26)}=14.53, p=0.0008$; post hoc Bonferroni, significant differences between scrambleamphetamine and the rest of the groups, $p<0.05)$. It is interesting to note that microinfusion of antimiR-218 alone does not increase Dcc mRNA expression beyond control levels. This finding is consistent with our previous results showing that 


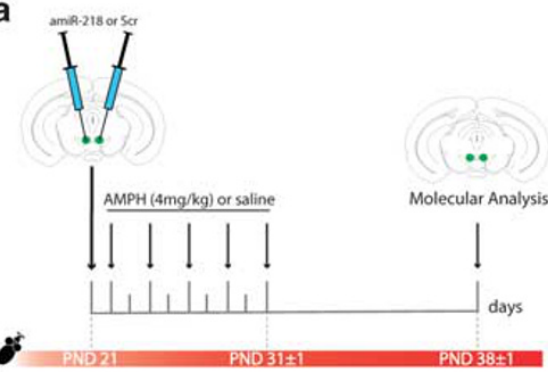

c

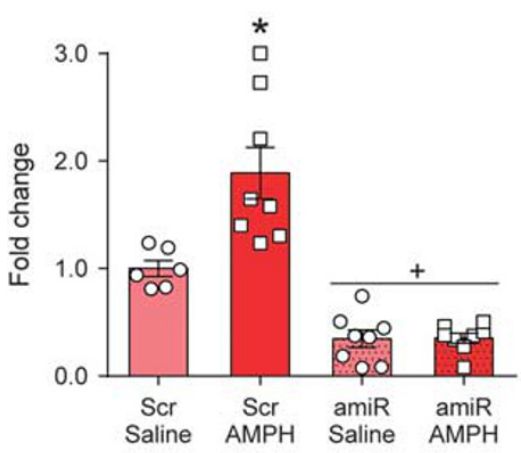

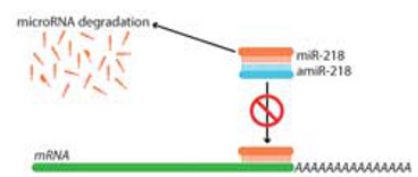

Dcc mRNA b

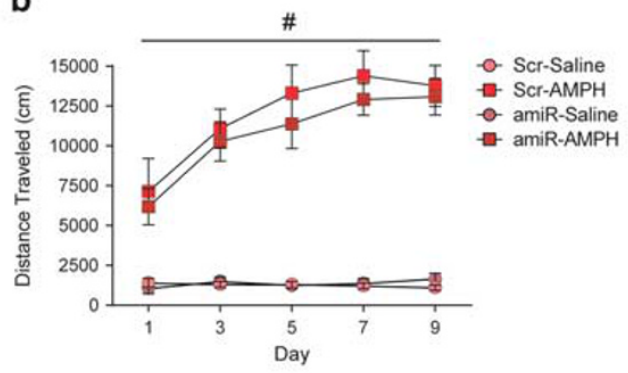

DCC Protein
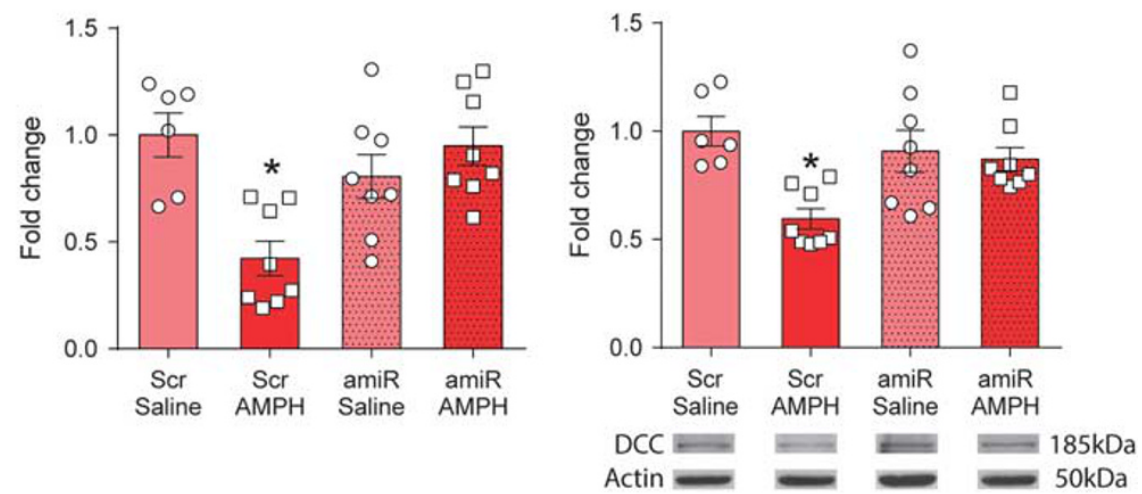

d

Robo1 mRNA

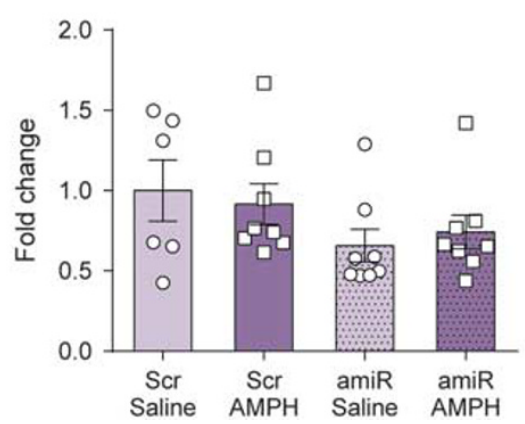

e

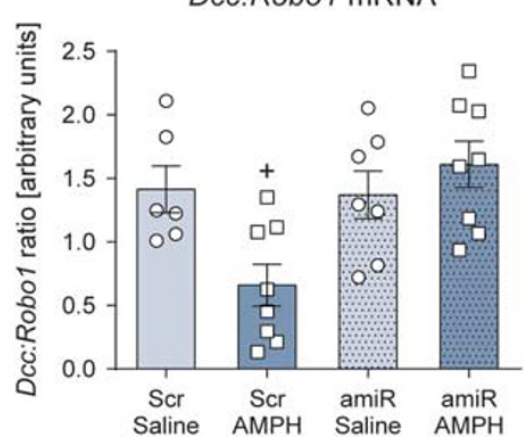

Figure 3 Amphetamine in adolescence recruits miR-218 to downregulate Dcc mRNA and protein expression in the VTA. (a) Left panel: timeline of antimiR-218 (amiR-2l8) or scramble (Scr) sequence microinfusions, amphetamine (AMPH) or saline treatment, and experimental procedures. Right panel: schematic representation of the mechanism of action of antagomiRs. (b) Behavioral activity during the 90 min test performed after each treatment injection, \# significantly different from saline-treated mice, $p<0.05$. (c) AMPH upregulates miR-2I 8 in Scr-treated mice, but not in those treated with antimiR-2I8. MiR-2I 8 levels are significantly reduced following antimir-218 infusion, regardless of drug exposure *significantly different from the other groups, $p<0.01$; ${ }^{+}$significantly different from Scr-Saline, $\left.p<0.05\right)$. AntimiR-2 18 infusion abolishes AMPH-induced downregulation of Dec mRNA and DCC protein expression in the VTA; *significantly different from the rest of the groups, $p<0.05$. (d) Robo I expression in the VTA is not altered by AMPH treatment or by antimiR-2 I 8 microinfusion. (e) AMPH in adolescence induces a significant shift in the Dcc:Robo I mRNA expression ratio in the VTA with a predominance of Robo I mRNA in amphetamine vs saline groups. This effect is abolished when miR-2। 8 degradation is induced; ${ }^{+}$significantly different from Scramble-Saline, $p<0.05$. All data are shown as mean $\pm \mathrm{SEM}$.

blockade of miR-218-DCC binding in a human cell line does not increase DCC mRNA levels beyond those see in control conditions (Torres-Berrío et al, 2017).

To verify that anitmiR-218 also abolishes the effects of amphetamine on DCC protein levels, we conducted western blot analysis in the same VTA samples. Indeed, amphetamine exposure in adolescence reduces DCC protein expression in mice with Scramble sequence microinfusions, but not in mice with antimiR-218 microinfusions (Figure 3c; twoway ANOVA: main effect of treatment, $F_{(1,26)}=9.84$, $p=0.0042$, significant microinfusion $\times$ treatment interaction,
$F_{(1,26)}=6.80, p=0.015$; post hoc Bonferroni, significant differences between scramble-amphetamine $v s$ all the other groups, $p<0.05)$. These results indicate that the repression of Dcc mRNA by miR-218 in the VTA impacts on protein translation. These results show, for the first time, that microRNAs can function as molecular mediators of the effects of stimulant drugs on gene in expression in rewardrelevant circuitry in adolescence.

Unlike Dcc and, as expected, Robo1 mRNA expression is not altered by amphetamine treatment regardless of microinfusion (Figure 3d; two-way ANOVA: microinfusion: $F_{(1,26)}=4.01$; 
treatment: $\quad F_{(1,26)}=8 \mathrm{e}-6 ; \quad$ microinfusion $\times$ treatment: $\left.F_{(1,26)}=0.43\right)$, demonstrating, again, that amphetamineinduced regulation of miR-218 targets $D c c$ selectively. However, in mice with scramble sequence microinfusion, amphetamine treatment led to a significant reduction in the relative Dcc:Robo1 mRNA expression ratio. This change was not observed in samples derived from mice with antimiR-218. (Figure 3e; two-way ANOVA: main effect of microinfusion: $F_{(1,25)}=6.28, p=0.019$, infusion $\times$ treatment interaction: $F_{(1,25)}=7.56, p=0.011$, post hoc Bonferroni, $p<0.05)$.

\section{Amphetamine in Adolescence Increases miR-218 in the VTA via Activation of D2 Receptors}

Activation of D2 receptors in VTA dopamine neurons is known to initiate a series of cellular and molecular events that lead to long-term neuronal and behavioral adaptations induced by amphetamine (Kalivas and Duffy, 1991; Vezina, 2004). Thus, we tested whether D2 receptor activation is required for the effects of amphetamine on miR-218 and Dcc mRNA expression (Figure 4a). Figure $4 \mathrm{~b}$ shows that raclopride pretreatment reduces amphetamine-induced locomotor activity (three-way ANOVA for repeated measures, main effect of pretreatment, $F_{(1,23)}=79.79, \quad p<0.0001 ; \quad$ of treatment $F_{(1,23)}=210.66$, $p<0.0001$, and of pretreatment $\times$ treatment interaction, $F_{(1,23)}=62.35, \quad p<0.0001$, post hoc Bonferroni; significant differences saline-amphetamine $v s$ all the other groups in the distance traveled each day and in raclopride-amphetamine $v s$ saline-amphetamine and raclopride-saline during the two last days of the treatment; $p<0.05)$.

Importantly, blockade of D2 receptors prevents amphetamine-induced increase in miR-218 (Figure 4c; twoway ANOVA, main effect of pretreatment $F_{(1,23)}=5.26$, $p=0.0316$ and significant pretreatment $\times$ treatment interaction, $F_{(1,23)}=5.35, p=0.030$; post hoc Bonferroni, $p<0.05$ ) and the reduction on Dcc mRNA expression in the VTA (Figure 4c; two-way ANOVA, main effect of pretreatment, $F_{(1,23)}=8.91, p=0.006$, treatment $F_{(1,23)}=10.93, p=0.003$ and significant pretreatment $\times$ treatment interaction, $F_{(1,23)}=4.67, p=0.041$; post hoc Bonferroni, $\left.p<0.05\right)$.

Mesolimbic but not mesocortical dopamine neurons, express high levels of DCC receptors across postnatal life (Manitt et al, 2013). Furthermore, we demonstrated that DCC receptors in mesolimbic dopamine neurons promote target recognition in the nucleus accumbens in adolescence, preventing them from ectopically innervating the medial prefrontal cortex (Reynolds et al, 2017). Thus, the fact that D2 receptors are necessary for the effects of amphetamine on VTA miR-218 and Dcc mRNA expression is particularly important because mesolimbic, but not mesocortical dopamine neurons express somatodendritic D2-like receptors (Lammel et al, 2008).

\section{Blockade of D1 Receptors Does Not Alter the Effects of Amphetamine in Adolescence on miR-218 and Dcc mRNA Expression in the VTA}

To further elucidate the mechanism by which amphetamine exposure in adolescence modulates the expression of miR-218 in the VTA we also assessed the effects of systemic administration of a D1 receptor antagonist. As shown in
Figure 4f, pretreatment with the D1 antagonist SCH 23390 before each amphetamine injection blocks drug-induced increase in locomotor activity (Three-way ANOVA for repeated measures, main effect of pretreatment, $F_{(1,20)}=245.40$, $p<0.0001$; of treatment $F_{(1,20)}=328.25, p<0.0001$, of pretreatment $\times$ treatment interaction, $F_{(1,20)}=210.64, p<0.0001$. Post hoc Bonferroni analysis revealed significant differences between saline-amphetamine $v s$ all the other groups, between $\mathrm{SCH}$ 23390-amphetamine vs saline-saline and between SCH 23390amphetamine $v s$ SCH 23390-saline on the first day of treatment; $p<0.05)$.

The molecular analysis indicates that blocking the D1 receptors does not affect amphetamine-induced increase in miR-218 (Figure 4g; two-way ANOVA, main effect of treatment, $F_{(1,20)}=25.73, p<0.0001$. Post hoc Bonferroni analysis revealed significant differences between salineamphetamine vs saline-saline, saline-amphetamine vs $\mathrm{SCH}$ 23390-saline, SCH 23390-amphetamine vs saline-saline and between SCH 23390-amphetamine vs SCH 23390-saline, $p<0.05)$ and reduction on Dcc mRNA expression in the VTA (Figure 4g; two-way ANOVA, main effect of treatment, $F_{(1,20)}=27.92, p<0.0001$. Post hoc Bonferroni analysis revealed significant differences between saline-amphetamine vs salinesaline, saline-amphetamine vs SCH 23390-saline, SCH 23390amphetamine $v s$ saline-saline and between SCH 23390amphetamine $v$ SCH 23390-saline, $p<0.05)$. Moreover, Robo1 mRNA is similar among the different treatments (Figure 4h; two-way ANOVA, pretreatment: $F_{(1,20)}=0.58$; treatment: $F_{(1,20)}=0.010$; pretreatment $\times$ treatment: $\left.F_{(1,20)}=0.38\right)$.

\section{DISCUSSION}

DCC signaling in dopamine neurons determines the development and function of the prefrontal cortex by controlling the extent of dopamine axons that continue to grow to this region during adolescence (Manitt et al, 2013, 2011; Reynolds et al, 2015, 2017). However, the precise mechanism that maintains and regulates the levels of DCC itself in dopamine neurons has remained unknown. Here we show that miR-218, a potent repressor of DCC (TorresBerrío et al, 2017), is expressed in VTA dopamine neurons and might be controlling their Dcc mRNA expression across postnatal life. Furthermore, we show that repeated exposure to amphetamine during early adolescence, but not in adulthood, suppresses Dcc mRNA and protein expression in VTA neurons through upregulating miR-218. This upregulation of miR-218 by amphetamine targets specifically $D c c$ and requires dopamine D2 receptor activation. Thus, miR-218 in the VTA, most likely in dopamine neurons, appears to be a molecular link between stimulant drugs in adolescence and changes in the expression of a key gene involved in prefrontal cortex and cognitive maturation (Reynolds et al, 2015, 2017). We propose that miR-218 expression in dopamine neurons is a marker of vulnerability to environmental risk factors in adolescence as well as a mediator of their enduring effects.

\section{The Dynamic Expression of miR-218 and Dcc in the VTA}

We have previously shown the pattern of DCC protein expression in VTA dopamine neurons changes during 
a

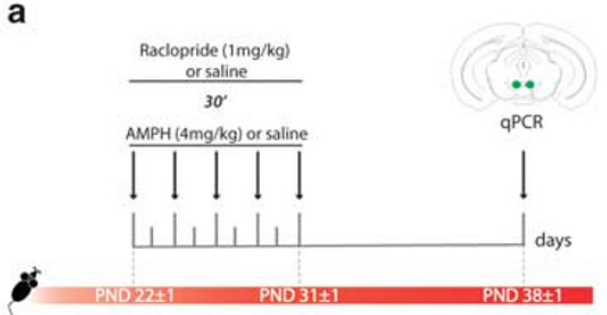

b

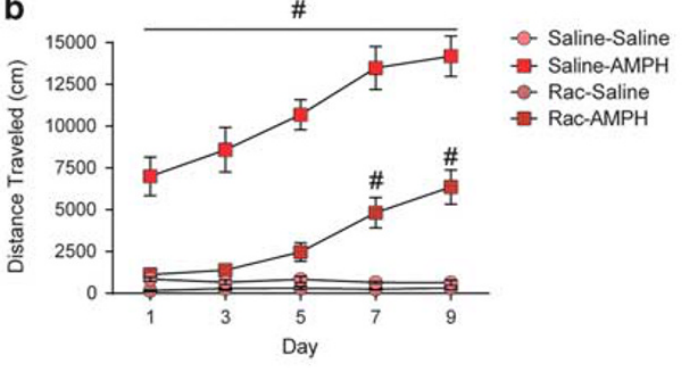

C

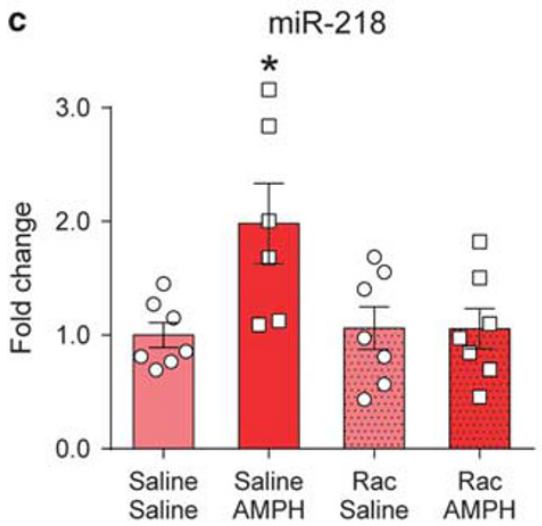

Dcc mRNA

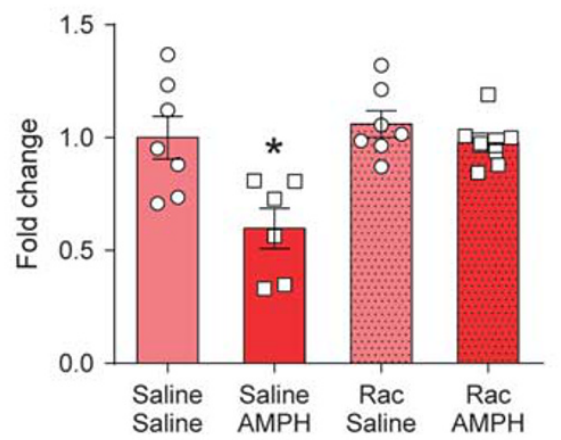

d

Robo1 mRNA
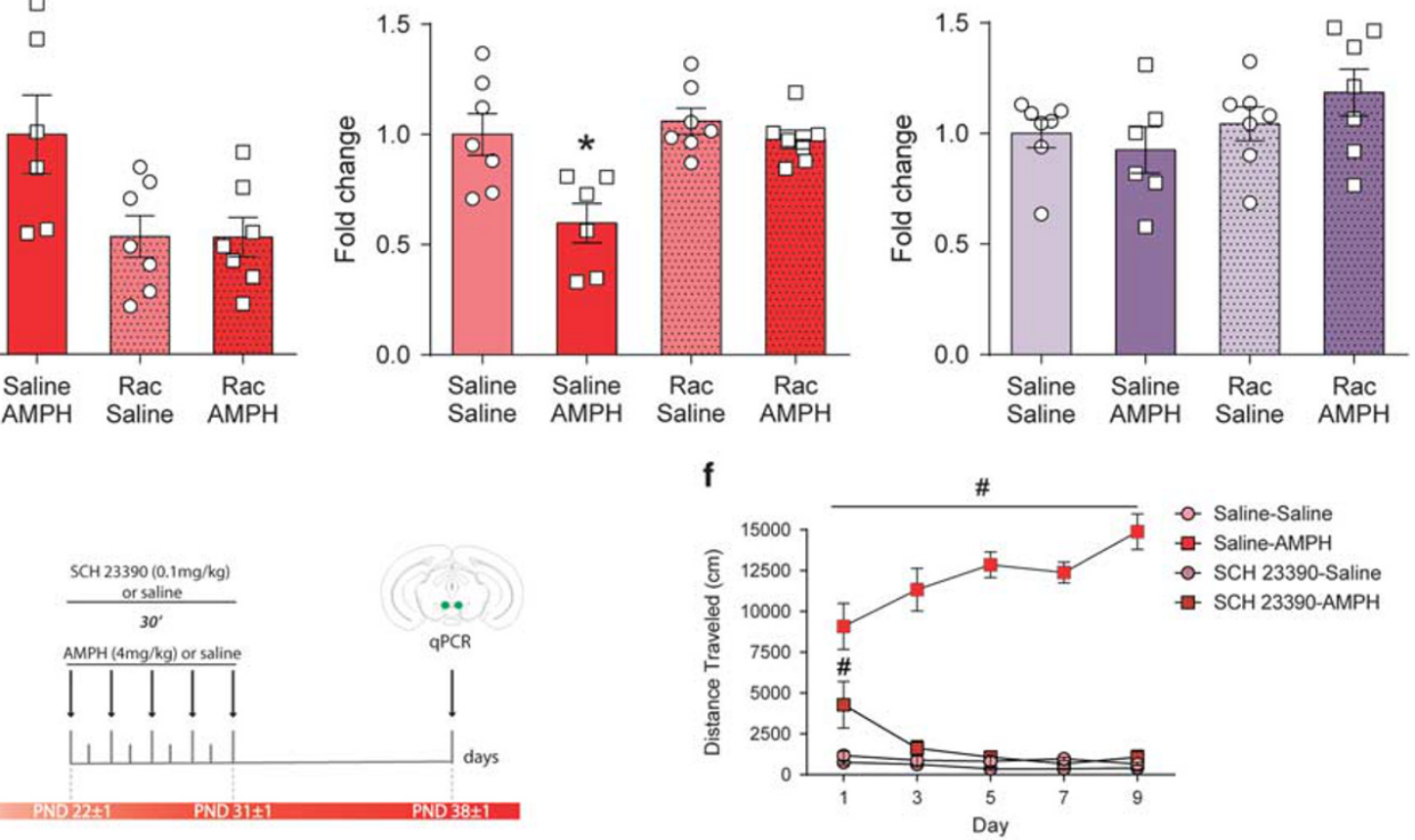

g

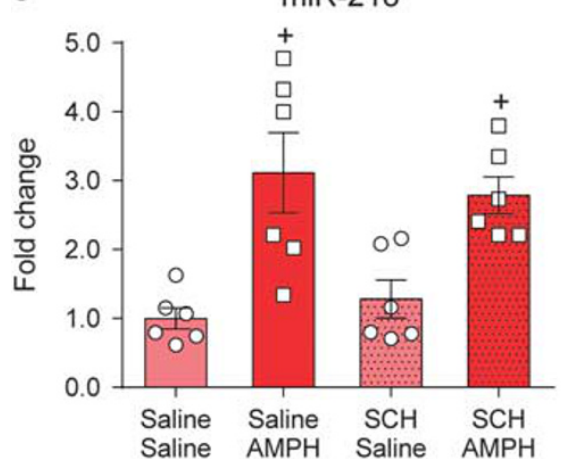

Dcc mRNA

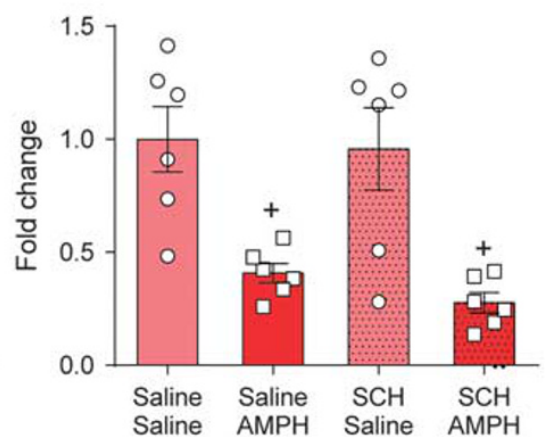

h

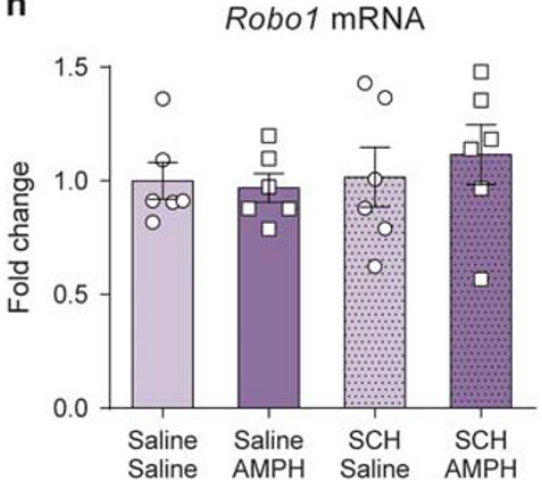

Figure 4 Amphetamine in adolescence requires D2 receptors activation to upregulate miR-2 I 8 and downregulate Dcc mRNA in the VTA. (a) Timeline of treatment and experimental procedures. (b) Locomotor activity during the 90 min test performed after each treatment injection; ${ }^{\#}$ significantly different from the other groups, $p<0.05$. (c) Amphetamine (AMPH)-induced upregulation of miR-2 8 and, in turn, downregulation of Dcc in the VTA requires D2 receptors activation; *significantly different from the other groups, $p<0.05$. (d) Robo I mRNA expression in the VTA is not altered by AMPH treatment or by raclopride (Rac) pretreatment. (e) Timeline of treatment and experimental procedures. (f) Locomotor activity during the 90 min test performed after each treatment injection; "\# significantly different from the other groups, $p<0.05$. (g) Blockade of D I receptors does not alter amphetamine-induced regulation of miR-2 8 or Dcc mRNA; ${ }^{+}$significantly different from saline-treated mice, $p<0.05$. (h) Robol mRNA expression in the VTA is not altered by AMPH treatment or SCH 23390 pretreatment. All data are shown as mean \pm SEM.

postnatal life, with high levels occurring in early adolescence but low levels in adulthood (Manitt et al, 2010). Our present data suggest that this dynamic expression is controlled at the transcription level (ie, Dcc mRNA expression) and, importantly, is maintained by miR-218. We have shown that miR-218 controls DCC mRNA and protein expression in prefrontal cortex pyramidal neurons in both humans and rodents (Torres-Berrío et al, 2017), and in fact DCC protein 
expression in this region also switches in adolescence (Goldman et al, 2013). Thus, we speculate that miR-218 may control the spatiotemporal expression of DCC and may be implicated in the adolescent maturation of rewardrelevant circuits. Future quantitative and subcellular fractionation studies will be conducted to further characterize the expression of miR-218 in the VTA.

Although the mechanisms controlling the fluctuation of VTA miR-218 levels over development remain to be determined, endogenous fluctuations in gonadal hormones are likely to play a role. Gonadal hormones may affect miR-218 by altering activity-dependent transcription of primiR-218, cleavage and translocation of pre-miR-218, and/or stability of the mature transcript (Joilin et al, 2014; Sambandan et al, 2017). Indeed, the expression of other microRNAs in the hippocampus has been shown to vary across postnatal life and to be sensitive to alterations in circulating levels of gonadal steroids (Kucherenko et al, 2012; Prins et al, 2014; Rao et al, 2013b, 2015). Future experiments are needed to determine whether gonadal hormones influence miR-218 expression on dopamine neurons during adolescence.

\section{miR-218 as a Potential Mediator of Amphetamine- Induced Regulation of DCC Receptors in the VTA}

There is an increasing number of studies showing that exposure to drugs, including ethanol, cocaine, and heroin, leads to changes in miRNA expression in reward-relevant brain regions of adult rodents (Darcq et al, 2015; EipperMains et al, 2011; Hollander et al, 2010; Im et al, 2010; Yan et al, 2017), and in fact, these would include changes in miR-218 expression in the striatum after repeated exposure to heroin and cocaine during adulthood in rats (EipperMains et al, 2011; Yan et al, 2017). Our study, however, goes a step further to show that the upregulation of miR-218 induced by amphetamine exposure during adolescence targets Dcc mRNA expression. Furthermore, this effect appears to be selective to $D c c$ because the expression of Robo1, which is the other guidance cue receptor target of miR-218, is unaltered by amphetamine. We also demonstrate how amphetamine regulates miR-218 and show that this regulation is restricted to adolescence.

In the VTA, dopamine neurons projecting to the nucleus accumbens, but not to the medial prefrontal cortex, express D2 receptors (Lammel et al, 2008). The activation of these autoreceptors initiates a series of cellular and molecular processes that lead to long-term neuronal and behavioral adaptations (Kalivas and Duffy, 1991; Vezina, 2004). In this study, we show that D2, but not the D1, receptor activation is required for the upregulation of $\mathrm{miR}-218$ expression by amphetamine in adolescence. This is consistent with previous reports showing that changes in D2 receptors expression in cultured renal cells is associated with changes in the expression of several microRNAs (Han et al, 2015). While the mechanisms mediating these effects are unknown, changes in neuronal activity may be at play (Sim et al, 2014). In fact, we suggest that systemic raclopride administration abolishes the effect of amphetamine on miR-218 by blocking D2 receptors specifically in VTA mesolimbic dopamine neurons. Indeed, amphetamine induces somatodendritic dopamine release in the VTA and we have shown that mesolimbic, but not mesocortical dopamine neurons, express DCC receptors. Furthermore, the lack of effect of the D1 antagonist on miR-218 upregulation by amphetamine supports the idea that the effects of raclopride are mediated by $\mathrm{D} 2$ receptors localized to dopamine neurons because dopamine cells do not express D1 receptors (Mansour et al, 1992). Nonetheless, at this point we cannot rule out the involvement of postsynaptic D2 receptors, indirectly affecting miR-218 expression in dopamine neurons.

A major strength of our study is that we used antagomir technology in vivo to demonstrate that miR-218 functions as molecular mediator of the effects of amphetamine on DCC expression. Although this strategy is effective when assessing short-term changes in miRNA expression, it has important limitations when assessing long-term effects. MiR-218 seems to regulate $D c c$ mRNA expression across postnatal life and it has been shown that a single intracerebroventricular infusion of antagomir can induce the degradation of microRNAs for at least 30 days (Nolan et al, 2014). Such a prolonged reduction of miR-218 would continue to influence DCC expression well into adulthood, making it difficult to assess the role of miR-218 in the enduring effects of drug exposure selectively in adolescence.

\section{Age Dependent Effects of Amphetamine on DCC Protein Expression in the VTA}

In previous studies we showed that amphetamine exposure in adulthood induces an increase in VTA DCC protein expression and that this increase is necessary for the development of drug-induced behavioral sensitization (Yetnikoff et al, 2010). In this study, however, we show that amphetamine exposure in adulthood does not alter Dcc mRNA expression. In contrast, amphetamine in adolescence downregulates both Dcc mRNA and DCC protein expression in the VTA. Thus, the present data suggest that not only the direction of the effects of amphetamine on DCC protein expression in the VTA are opposite between early adolescence and adulthood, but that also different mechanisms may be recruited. The fact that amphetamine in adolescence, but not in adulthood, upregulates miR-218 in the VTA may be an important mechanism accounting for age effects of the drug on DCC protein expression.

\section{CONCLUSION}

Considerable efforts are being made to identify biomarkers of vulnerability, particularly during adolescence. MicroRNAs are emerging as promising targets since they are highly stable in peripheral fluids (Chakraborty and Das, 2016), with patters of expression in these fluids matching those observed in the tissue of origin, including brain (Issler et al, 2014; Jin et al, 2013; Rao et al, 2013a). Thus, miR-218 has translational potential as both a mediator and a predictor biomarker, especially since it can be readily detected in blood, urine, and saliva samples in humans (Weber et al, 2010).

\section{FUNDING AND DISCLOSURE}

This work was supported by the National Institute on Drug Abuse (R01DA037911 to CF; F31DA041188 to LMR), the 
Natural Science and Engineering Research Council of Canada (2982226 to CF), the Canadian Institutes of Health Research (MOP-74709 to CF). CF is a research scholar of the Fonds de Recherche du Québec-Santé. SC was supported by the Conrad F. Harrington postdoctoral fellowship. The authors declare no conflict of interest.

\section{AUTHOR CONTRIBUTIONS}

SC and CF conceived the experiments. SC, AA, and CF designed the experiments. SC and JMR-L performed the developmental neuroanatomical and molecular characterization, drug, and antagomir experiments. SS performed all the stereotaxic surgeries. DN contributed to the in situ hybridization experiments. AT-B and LMR provided technical training necessary to perform part of the experiments. SC, JMR-L, AA and CF analyzed the results. SC, AA and CF wrote the paper.

\section{REFERENCES}

Aranda PS, LaJoie DM, Jorcyk CL (2012). Bleach gel: a simple agarose gel for analyzing RNA quality. Electrophoresis 33: 366-369.

Butovsky O, Jedrychowski MP, Moore CS, Cialic R, Lanser AJ, Gabriely $G$ et al (2014). Identification of a unique TGF-betadependent molecular and functional signature in microglia. Nat Neurosci 17: 131-143.

Chakraborty C, Das S (2016). Profiling cell-free and circulating miRNA: a clinical diagnostic tool for different cancers. Tumour Biol 37: 5705-5714.

Codocedo JF, Inestrosa NC (2016). Environmental control of microRNAs in the nervous system: Implications in plasticity and behavior. Neurosci Biobehav Rev 60: 121-138.

Darcq E, Warnault V, Phamluong K, Besserer GM, Liu F, Ron D (2015). MicroRNA-30a-5p in the prefrontal cortex controls the transition from moderate to excessive alcohol consumption. Mol Psychiatry 20: 1261.

Dudanova I, Klein R (2013). Integration of guidance cues: parallel signaling and crosstalk. Trends Neurosci 36: 295-304.

Eipper-Mains JE, Kiraly DD, Palakodeti D, Mains RE, Eipper BA, Graveley BR (2011). microRNA-Seq reveals cocaine-regulated expression of striatal microRNAs. RNA 17: 1529-1543.

Fan X, Hess EJ (2007). D2-like dopamine receptors mediate the response to amphetamine in a mouse model of ADHD. Neurobiol Dis 26: 201-211.

Flores C (2011). Role of netrin-1 in the organization and function of the mesocorticolimbic dopamine system. J Psychiatry Neurosci 36: 296-310.

Goldman JS, Ashour MA, Magdesian MH, Tritsch NX, Harris SN, Christofi $\mathrm{N}$ et al (2013). Netrin-1 promotes excitatory synaptogenesis between cortical neurons by initiating synapse assembly. J Neurosci 33: 17278-17289.

Grant BF, Dawson DA (1998). Age of onset of drug use and its association with DSM-IV drug abuse and dependence: results from the National Longitudinal Alcohol Epidemiologic Survey. J Subst Abuse 10: 163-173.

Han F, Konkalmatt P, Chen J, Gildea J, Felder RA, Jose PA et al (2015). MiR-217 mediates the protective effects of the dopamine D2 receptor on fibrosis in human renal proximal tubule cells. Hypertension 65: 1118-1125.

He M, Liu Y, Wang X, Zhang MQ, Hannon GJ, Huang ZJ (2012). Cell-type-based analysis of microRNA profiles in the mouse brain. Neuron 73: 35-48.
Hollander JA, Im HI, Amelio AL, Kocerha J, Bali P, Lu Q et al (2010). Striatal microRNA controls cocaine intake through CREB signalling. Nature 466: 197-202.

Hollins SL, Cairns MJ (2016). MicroRNA: small RNA mediators of the brains genomic response to environmental stress. Prog Neurobiol 143: 61-81.

Im HI, Hollander JA, Bali P, Kenny PJ (2010). MeCP2 controls BDNF expression and cocaine intake through homeostatic interactions with microRNA-212. Nat Neurosci 13: 1120-1127.

Issler O, Chen A (2015). Determining the role of microRNAs in psychiatric disorders. Nat Rev Neurosci 16: 201-212.

Issler O, Haramati S, Paul ED, Maeno H, Navon I, Zwang R et al (2014). MicroRNA 135 is essential for chronic stress resiliency, antidepressant efficacy, and intact serotonergic activity. Neuron 83: 344-360.

Jin XF, Wu N, Wang L, Li J (2013). Circulating microRNAs: a novel class of potential biomarkers for diagnosing and prognosing central nervous system diseases. Cell Mol Neurobiol 33: 601-613.

Joilin G, Guevremont D, Ryan B, Claudianos C, Cristino AS, Abraham WC et al (2014). Rapid regulation of microRNA following induction of long-term potentiation in vivo. Front Mol Neurosci 7: 98.

Kalivas PW, Duffy P (1991). Comparison of somatodendritic and axonal mesolimbic dopamine release using in vivo dialysis. J Neurochem 56: 961-967.

Krutzfeldt J, Kuwajima S, Braich R, Rajeev KG, Pena J, Tuschl T et al (2007). Specificity, duplex degradation and subcellular localization of antagomirs. Nucleic Acids Res 35: 2885-2892.

Kucherenko MM, Barth J, Fiala A, Shcherbata HR (2012). Steroidinduced microRNA let-7 acts as a spatio-temporal code for neuronal cell fate in the developing Drosophila brain. EMBO J 31: 4511-4523.

Laviola G, Macri S, Morley-Fletcher S, Adriani W (2003). Risktaking behavior in adolescent mice: psychobiological determinants and early epigenetic influence. Neurosci Biobehav Rev 27: 19-31.

Lammel S, Hetzel A, Hackel O, Jones I, Liss B, Roeper J (2008). Unique properties of mesoprefrontal neurons within a dual mesocorticolimbic dopamine system. Neuron 57: 760-773.

Manitt C, Eng C, Pokinko M, Ryan RT, Torres-Berrio A, Lopez JP et al (2013). DCC orchestrates the development of the prefrontal cortex during adolescence and is altered in psychiatric patients. Transl Psychiatry 3: e338.

Manitt C, Labelle-Dumais C, Eng C, Grant A, Mimee A, Stroh T et al (2010). Peri-pubertal emergence of UNC-5 homologue expression by dopamine neurons in rodents. PLoS ONE 5: e11463.

Manitt C, Mimee A, Eng C, Pokinko M, Stroh T, Cooper HM et al (2011). The netrin receptor DCC is required in the pubertal organization of mesocortical dopamine circuitry. J Neurosci 31: 8381-8394.

Mansour A, Meador-Woodruff JH, Zhou Q, Civelli O, Akil H, Watson SJ (1992). A comparison of D1 receptor binding and mRNA in rat brain using receptor autoradiographic and in situ hybridization techniques. Neuroscience 46: 959-971.

Marillat V, Cases O, Nguyen-Ba-Charvet KT, Tessier-Lavigne M, Sotelo C, Chedotal A (2002). Spatiotemporal expression patterns of slit and robo genes in the rat brain. J Comp Neurol 442: 130-155.

McCabe SE, West BT, Morales M, Cranford JA, Boyd CJ (2007). Does early onset of non-medical use of prescription drugs predict subsequent prescription drug abuse and dependence? Results from a national study. Addiction 102: 1920-1930.

Money KM, Stanwood GD (2013). Developmental origins of brain disorders: roles for dopamine. Front Cell Neurosci 7: 260.

Mukherji S, Ebert MS, Zheng GX, Tsang JS, Sharp PA, van Oudenaarden A (2011). MicroRNAs can generate thresholds in target gene expression. Nat Genet 43: 854-859.

Nolan K, Mitchem MR, Jimenez-Mateos EM, Henshall DC, Concannon CG, Prehn JH (2014). Increased expression of microRNA-29a in ALS mice: functional analysis of its inhibition. J Mol Neurosci 53: 231-241. 
Paxinos G, Franklin KBJ (2001). The mouse brain in stereotaxic coordinates, 2nd edn. Academic Press: NY.

Prins SA, Przybycien-Szymanska MM, Rao YS, Pak TR (2014). Longterm effects of peripubertal binge EtOH exposure on hippocampal microRNA expression in the rat. PLoS ONE 9: e83166.

Rao P, Benito E, Fischer A (2013a). MicroRNAs as biomarkers for CNS disease. Front Mol Neurosci 6: 39.

Rao YS, Mott NN, Wang Y, Chung WC, Pak TR (2013b). MicroRNAs in the aging female brain: a putative mechanism for age-specific estrogen effects. Endocrinology 154: 2795-2806.

Rao YS, Pak TR (2016). microRNAs and the adolescent brain: filling the knowledge gap. Neurosci Biobehav Rev 70: 313-322.

Rao YS, Shults CL, Pinceti E, Pak TR (2015). Prolonged ovarian hormone deprivation alters the effects of 17beta-estradiol on microRNA expression in the aged female rat hypothalamus. Oncotarget 6: 36965-36983.

Reynolds LM, Makowski CS, Yogendran SV, Kiessling S, Cermakian $\mathrm{N}$, Flores C (2015). Amphetamine in adolescence disrupts the development of medial prefrontal cortex dopamine connectivity in a DCC-dependent manner. Neuropsychopharmacology 40: 1101-1112.

Reynolds LM, Pokinko M, Torres-Berrio A, Cuesta S, Lambert LC, Del Cid Pellitero E et al (2017). DCC receptors drive prefrontal cortex maturation by determining dopamine axon targeting in adolescence. Biol Psychiatry. (in press); doi: 10.1016/j.biopsych.2017.06.009.

Sambandan S, Akbalik G, Kochen L, Rinne J, Kahlstatt J, Glock C et al (2017). Activity-dependent spatially localized miRNA maturation in neuronal dendrites. Science 355: 634-637.

Schneider M (2013). Adolescence as a vulnerable period to alter rodent behavior. Cell Tissue Res 354: 99-106.

Sim SE, Bakes J, Kaang BK (2014). Neuronal activity-dependent regulation of microRNAs. Mol Cells 37: 511-517.

Small EM, Sutherland LB, Rajagopalan KN, Wang S, Olson EN (2010). MicroRNA-218 regulates vascular patterning by modulation of Slit-Robo signaling. Circ Res 107: 1336-1344.
Spear LP (2000). The adolescent brain and age-related behavioral manifestations. Neurosci Biobehav Rev 24: 417-463.

Sun AX, Crabtree GR, Yoo AS (2013). MicroRNAs: regulators of neuronal fate. Curr Opin Cell Biol 25: 215-221.

Swendsen J, Burstein M, Case B, Conway KP, Dierker L, He J et al (2012). Use and abuse of alcohol and illicit drugs in US adolescents: results of the National Comorbidity SurveyAdolescent Supplement. Arch Gen Psychiatry 69: 390-398.

Thiebes KP, Nam H, Cambronne XA, Shen R, Glasgow SM, Cho $\mathrm{HH}$ et al (2015). miR-218 is essential to establish motor neuron fate as a downstream effector of Isl1-Lhx3. Nat Commun 6: 7718.

Tirelli E, Laviola G, Adriani W (2003). Ontogenesis of behavioral sensitization and conditioned place preference induced by psychostimulants in laboratory rodents. Neurosci Biobehav Rev 27: 163-178.

Torres-Berrío A, Lopez JP, Bagot RC, Nouel D, Dal BoG, Cuesta S et al (2017). DCC confers susceptibility to depression-like behaviors in humans and mice and is regulated by miR-218. Biol Psychiatry 81: 306-315.

Vezina P (2004). Sensitization of midbrain dopamine neuron reactivity and the self-administration of psychostimulant drugs. Neurosci Biobehav Rev 27: 827-839.

Weber JA, Baxter DH, Zhang S, Huang DY, Huang KH, Lee MJ et al (2010). The microRNA spectrum in 12 body fluids. Clin Chem 56: $1733-1741$.

Yan B, Hu Z, Yao W, Le Q, Xu B, Liu X et al (2017). MiR-218 targets MeCP2 and inhibits heroin seeking behavior. Sci Rep 7: 40413.

Yetnikoff L, Almey A, Arvanitogiannis A, Flores C (2011). Abolition of the behavioral phenotype of adult netrin-1 receptor deficient mice by exposure to amphetamine during the juvenile period. Psychopharmacology (Berl) 217: 505-514.

Yetnikoff L, Eng C, Benning S, Flores C (2010). Netrin-1 receptor in the ventral tegmental area is required for sensitization to amphetamine. Eur J Neurosci 31: 1292-1302. 